\title{
Evaluation of the development level of construction industry based on factor analysis in Sichuan province, China
}

\author{
Yuliang Fan ${ }^{1, a}$, Fenghui Chen ${ }^{1, b^{*}}$ and Qiong Shen ${ }^{2, c}$ \\ ${ }^{1}$ College of Civil Engineering, Sichuan Agricultural University, Dujiangyan, China \\ ${ }^{2}$ College of architecture and Urban-Rural Planning, Sichuan Agricultural University, Dujiangyan, \\ China \\ afylsicau@126.com, ${ }^{b}$ cfenghui@sicau.edu.cn, ${ }^{\mathrm{c}} 727202860 @ q q . c o m$
}

\begin{abstract}
Keywords: Construction industry; Sichuan province; Development level
Abstract. To understand the development level status of construction industry in Sichuan province, China, this study selected 11 economical indicators of construction industry to evaluate the development level of construction industry in 21 cities (prefectures) of Sichuan province by using factors analysis. The results show that 11 economic indicators can be induced to 2 comprehensive factors (i.e., scale factor and efficiency factor). The development level status of construction industry of 21 cities (prefectures) can be divided into 4 categories. The development level of Chengdu was the highest, and the development level of Aba, Yaan and Ganzi were the lowest. The study indicates that the overall development level of construction industry in Sichuan province is dependent on scale factor. The difference of the development level of construction industry over the province is obvious.
\end{abstract}

\section{Introduction}

In 2013, the total output value of construction industry (CI) of Sichuan province, China reached 7, 277 billion Yuan. The value-added exceeded 2,000 billion Yuan, which accounted for $7.62 \%$ of the provincial GDP and $10.60 \%$ of the provincial economic contribution rate $[1,2]$. Accompanying with the advancement of the western development strategy of China, the CI scale in Sichuan province will increase continuously. In this case, evaluation of the CI development status in Sichuan province is benefit to the reasonable and stable CI development in the future.

The CI development level was affected by level of investment, enterprise scale, technological capability, capacity of equipment, and market scale etc. [3]. Therefore, multi-factors evaluation model was often adopted to evaluate the CI development level. At present, there were a large number of methods to establish the multi-factors evaluation model, such as analytic hierarchy process [4], comprehensive index method [5], artificial neural network [6], grey correlation analysis method [7], factor analysis (FA) [8], etc. In these methods, FA not only can reduce the numbers of evaluation indicators through principal component analysis to realize the comprehensive evaluation, but also can maintain the vast majority of information of evaluation indicators [9, 10]. Furthermore, FA can avoid the interference of anthropic factor in the decision process of the weights of comprehensive factors owing to the reason that the weights of comprehensive factors are dependent on their contribution rate in FA [11]. Thus FA is widely used in previous studies.

This study selected $11 \mathrm{CI}$ economical indicators to evaluate the CI development level in 21 cities (prefectures) of Sichuan province by using factors analysis. The aim of the study is to grasp the realities of the situation of CI development level in Sichuan province and provide references for reasonable and stable CI development in this area.

\section{Materials and Methods}

Technical route. The study took 21 cities (prefectures) of Sichuan province as evaluation units. Firstly, $11 \mathrm{CI}$ economical indicators were selected. Secondly, the values of the $11 \mathrm{CI}$ economical indicators of each unit were acquired and used to establish an indicator data matrix, which composed of all values of the $11 \mathrm{CI}$ economical indicators of all 21 evaluation units. Thirdly, FA was used to reduce 
the dimension of the data matrix, obtain the comprehensive factors and calculate the scores of the comprehensive factors of each unit. Then the total score of each evaluation unit was computed. Finally, 21 evaluation units were classified and analyzed based on the total scores.

Selection of indicator. Five aspects, namely level of investment, enterprise scale, technological capability, capacity of equipment, and market scale, were considered in the selection process of CI indicators. In this study, 11 indicators were selected. The $11 \mathrm{CI}$ indicators were completed acreage $\left(\mathrm{x}_{1}\right.$, $\left.10^{4} \mathrm{~m}^{2}\right)$, construction acreage $\left(\mathrm{x}_{2}, 10^{4} \mathrm{~m}^{2}\right)$, installed power ratio $\left(\mathrm{x}_{3}, \mathrm{Kw} /\right.$ person), number of employees $\left(\mathrm{x}_{4}\right.$, person), number of construction enterprises $\left(\mathrm{x}_{5}\right.$, piece $)$, technical facility ratio $\left(\mathrm{x}_{6}\right.$, Yuan/person), total profits $\left(\mathrm{x}_{7}, 10^{4}\right.$ Yuan), total amount of profit and tax $\left(\mathrm{x}_{8}, 10^{4}\right.$ Yuan), enterprise assets $\left(\mathrm{x}_{9}, 10^{4}\right.$ Yuan), total number of machinery at the end of the year $\left(\mathrm{x}_{10}, \mathrm{set}\right)$, and total output value $\left(\mathrm{x}_{11}, 10^{4}\right.$ Yuan). The values of the indicators of each evaluation unit were adopted from the statistical yearbook of Sichuan province in 2014 [1].

Factor analysis. The main processes of FA included KMO test of matrix, calculation of eigenvalue of matrix, calculation of contribution rate of eigenvalue and accumulative contribution rate, calculation of loading matrix of rotation factor, acquirement and explanation of comprehensive factors. The detailed procedures of FA can be found in reference [12].The study used SPSS 19.0 for FA.

Calculation of total score. The total score of each evaluation unit was calculated as equation (1).

$$
T S=\left(a_{1} \cdot S_{1}+a_{2} S_{2}+\mathrm{L} a_{n} S_{n}\right) /\left(a_{1}+a_{2}+\mathrm{L} a_{n}\right)
$$

Where $T S$ is the total score of each evaluation unit. $a_{n}$ is contribution rate of comprehensive factor $\mathrm{n} ; s_{n}$ is the score of factor $n$ of each evaluation unit.

\section{Results and Discussion}

KMO test. The KMO value of the established data matrix is 0.819 . When KMO value is between 0.8 and 0.9, the data matrix is applicable for FA [11]. Consequently, the established indicator data matrix in the study is suitable for FA.

Eigenvalue of matrix and contribution rate of eigenvalue. Table 1 shows the eigenvalues and their contribution rates of the indicator data matrix. According to choosing basis of principle component that the eigenvalue of principle component need to be more than 1 , the selected 11 indicators can be attributed to 2 comprehensive factors according to Table 1, respectively. In table 1, the contribution rate of the 2 factors was $86.344 \%$ and $11.212 \%$, respectively. Furthermore, the accumulative contribution rate of the 2 factors was $97.556 \%$. The results indicate that the 2 factors cover $97.556 \%$ information of the 11 indicators. Therefore, 11 indicators can be represented with the 2 factors.

Table 1 the eigenvalue of indicator data matrix and contribution rate of eigenvalue

\begin{tabular}{|c|c|c|c|c|c|}
\hline $\begin{array}{c}\text { Principal } \\
\text { component }\end{array}$ & Eigenvalue & $\begin{array}{c}\text { Contribution rate } \\
(\%)\end{array}$ & $\begin{array}{c}\text { Principal } \\
\text { component }\end{array}$ & Eigenvalue & $\begin{array}{c}\text { Contribution rate } \\
(\%)\end{array}$ \\
\hline 1 & 9.498 & 86.344 & 7 & 0.014 & 0.130 \\
\hline 2 & 1.233 & 11.212 & 8 & 0.009 & 0.082 \\
\hline 3 & 0.091 & 0.829 & 9 & 0.004 & 0.034 \\
\hline 4 & 0.076 & 0.691 & 10 & 0.001 & 0.009 \\
\hline 5 & 0.054 & 0.495 & 11 & 0.000 & 0.001 \\
\hline 6 & 0.019 & 0.173 & & & \\
\hline
\end{tabular}

Rotated factor loading-matrix and explanation of factor. Table 2 shows the rotated factor loading-matrix of the indicator data matrix. According to the loading of each indicator in table 2, it can be concluded that factor 1 included 9 indicators (i.e., $\mathrm{x}_{1}, \mathrm{x}_{2}, \mathrm{x}_{4}, \mathrm{x}_{5}, \mathrm{x}_{7}, \mathrm{x}_{8}, \mathrm{x}_{9}, \mathrm{x}_{10}$, and $\mathrm{x}_{11}$ ) and factor 2 included 2 indicators (i.e., $\mathrm{x}_{3}$ and $\mathrm{x}_{6}$ ). For factor 1 , the 9 indicators reflect $\mathrm{CI}$ input and output status. Thus factor 1 can be explained as scale factor. For factor 2, the 2 indicators reflect the CI technology 
level. Therefore, factor 2 can be explained as efficiency factor. In addition, in the table 1 , the contribution rate of factor 1 was $86.334 \%$, and the contribution rate of factor 2 was only $11.212 \%$. The result indicates that the CI development level in Sichuan province is influenced by scale factor. In this case, there need to increase the input of technical level in the following CI development in Sichuan province for the reasonable and stable CI development in the future.

Table 2 Rotated factor loading-matrix of indicator data matrix

\begin{tabular}{|c|c|c|c|c|c|}
\hline \multirow{2}{*}{ Indicator } & \multicolumn{2}{|c|}{ Factor } & \multirow{2}{*}{ Indicator } & \multicolumn{2}{c|}{ Factor } \\
\cline { 2 - 3 } & Factors 1 & Factors 2 & & Factors 1 & Factors 2 \\
\hline $\mathrm{x}_{1}$ & 0.952 & 0.177 & $\mathrm{x}_{7}$ & 0.964 & 0.225 \\
\hline $\mathrm{x}_{2}$ & 0.969 & 0.199 & $\mathrm{x}_{8}$ & 0.968 & 0.231 \\
\hline $\mathrm{x}_{3}$ & 0.050 & 0.989 & $\mathrm{x}_{9}$ & 0.956 & 0.272 \\
\hline $\mathrm{x}_{4}$ & 0.984 & 0.130 & $\mathrm{x}_{10}$ & 0.966 & 0.210 \\
\hline $\mathrm{x}_{5}$ & 0.966 & 0.168 & $\mathrm{x}_{11}$ & 0.971 & 0.226 \\
\hline $\mathrm{x}_{6}$ & 0.628 & 0.750 & & & \\
\hline
\end{tabular}

The scores of factors and total score of each evaluation unit. Table 3 shows the scores of factors and total scores of 21 evaluation units. On factor 1, the scores of the rest of evaluation units were negative except of Chengdu, Luzhou, Mianyang, Nanchong, Deyang and Yibin. On factor 2, the scores of the rest of evaluation units were negative except of Chengdu, Guangan, Panzihua, Leshan, Guangyuan, Yaan,and Aba. The negative score of an evaluation unit on a factor represents that the development level of the unit is low on the factor aspect. In table 3, Chengdu got the maximum total score, whereas Ganzi got the minimum total score. The result indicates that the CI development level of Chengdu is the highest and Ganzi is the lowest. However, it is worth noting that the score of Ganzi on factor 2 was positive, and the score of Ganzi exceeded that of Chengdu. The result implies that the technical level of Ganzi is higher than Chengdu. In the table 3, the score of Ganzi on factor 1 was the minimum. The result indicates that the CI input and output of Ganzi is lower than those of other units. This may be a reason that the score of Ganzi on factor 2 is the maximum.

Table 3 The scores of factors and total scores of 21 evaluation units

\begin{tabular}{|c|c|c|c|c|c|c|c|}
\hline Unit & $\begin{array}{c}\text { Score on } \\
\text { factor 1 }\end{array}$ & $\begin{array}{c}\text { Score on } \\
\text { factor 2 }\end{array}$ & $\begin{array}{c}\text { Total } \\
\text { score }\end{array}$ & Unit & $\begin{array}{c}\text { Score on } \\
\text { factor 1 }\end{array}$ & $\begin{array}{c}\text { Score on } \\
\text { factor 2 }\end{array}$ & $\begin{array}{c}\text { Total } \\
\text { score }\end{array}$ \\
\hline Chengdu & 4.115 & 1.341 & 3.703 & Ziyang & -0.098 & -0.724 & -0.166 \\
\hline Luzhou & 0.306 & -1.034 & 0.148 & Bazhong & -0.148 & -0.570 & -0.192 \\
\hline Mianyang & 0.159 & -0.694 & 0.060 & Neijiang & -0.253 & -0.298 & -0.252 \\
\hline Nanchong & 0.084 & -0.249 & 0.045 & Liangshan & -0.274 & -0.190 & -0.258 \\
\hline Deyang & 0.029 & -0.430 & -0.023 & Panzhihua & -0.357 & 0.409 & -0.262 \\
\hline Guangan & -0.098 & 0.316 & -0.049 & Leshan & -0.358 & 0.223 & -0.284 \\
\hline Yibin & 0.044 & -0.785 & -0.050 & Guangyuan & -0.370 & 0.099 & -0.308 \\
\hline Dazhou & -0.055 & -0.380 & -0.090 & Aba & -0.404 & -0.253 & -0.377 \\
\hline Meishan & -0.101 & -0.086 & -0.097 & Yaan & -0.921 & 1.870 & -0.586 \\
\hline Zigong & -0.053 & -0.921 & -0.149 & Ganzi & -1.153 & 3.069 & -0.651 \\
\hline Suining & -0.093 & -0.712 & -0.160 & & & & \\
\hline
\end{tabular}

According to the total scores in table 3, the 21 evaluation cities of Sichuan province can be divided into the four types of area. The first type of area, where the total scores were more than -0.030 , included Chengdu, Luzhou, Mianyang, Nanchong and Deyang. The results indicate the advanced cities mainly concentrated on and around Chengdu, which is the capital city of Sichuan province, for CI development level. The second type of area, where the total scores were between -0.030 and -0.200 , included Guangan, Yibin, Dazhou, Meishan, Zigong, Suining, Ziyang and Bazhong. The scores of these cites on factor 1 and 2 were further front. Therefore, there is still a big space to development and 
promotion of CI development level. The CI development of this area is benefit to rapid CI development in Sichuan province in recent years. The third type of area, where the total scores were between -0. 200 and -0.350 , included Neijiang, Liangshan, Panzihua, Leshan and Guangyuan. In these cities, the improvement of construction technology should be paid special attention. The fourth type of area, where the total scores were less than -0.350, included Aba, Yaan and Ganzi. These cities need to increase the investment of construction scale for realizing rapid CI development.

\section{Conclusions}

The study evaluated the CI development level in 21 cities (prefectures) of Sichuan province by using factors analysis. The results show the CI development level in Sichuan province is affected by scale factor. In the future, there need to increase input of technical level in the following CI development of Sichuan province. In the ranking of CI development level of 21 cities (prefectures), Chengdu was the first and Ganzi was the last. The 21 evaluation cities of Sichuan province can be divided into the four types of area. The difference of the CI development level over the province is obvious.

\section{References}

[1] Sichuan Provincial Bureau of Statistics: Sichuan Statistical Yearbook (China Statistics Press, China 2014) (In Chinese)

[2] Sichuan Provincial Bureau of Statistics: Statistical bulletin of the national economic and social development of Sichuan province in 2013 (China Statistics Press, China 2014). (In Chinese)

[3] M. Wang, G. Liu and F. Deng: Chin Civ Eng. Vol. 44(2011), p. 157 (In Chinese)

[4] T.L.Saaty: Int. J. Serv. Sci. Vol. 1 (2008), p. 83

[5] F. Zhou and Z. Liao: Chin. J. Hosp. Adm., Vol .16(2000), p. 24 (In Chinese)

[6] L. Liu and W. Yan: J. Chongqing Jianzhu Univ. Vol. 27(2005), p: 97 (In Chinese)

[7] G.W. Wei: Expert Syst. Appl. Vol. 38(2011), p. 4824

[8] L. Lei and L. Nan: Chin. Civil Eng. J. Vol. 42(2009), p. 20 (in Chinese)

[9] X. Peng and M. Gao: Res. Fin. Econ. Issues Vol. 11(2014), p. 68. (in Chinese)

[10] J. IJmker, G. Stauch, K. Hartmann, B. Diekmannc, E. Dietzeb, S. Opitzc, B.Wünnemann and F. Lehmkuhl: J. Asian Earth Sci. Vol.44(2012), p. 176

[11]J. Li: Geogr. Res. Vol. 27(2008), p. 659 (in Chinese)

[12]L. Shi: SPSS19.0 Statistical Analysis from Entry to Master (Tsinghua University press, China 2012) (in Chinese)

[13]N. Wang, H. Li, X. Tang and X. Zhong: J. Xi'an Univ. Arch. Tech. Vol. 42(2010), p. 590 (in Chinese) 